\title{
Identifying Functional Adenovirus-Host Interactions Using Tandem Mass Spectrometry
}

\author{
Anuj Gaggar, Dmitry Shayakhmetov, and André Lieber
}

\begin{abstract}
Summary
We describe a systematic, high-throughput approach to identify proteins involved in functional adenovirus (Ad)-host interactions in vitro and in vivo. We were particularly interested in identifying cellular proteins that interact with fiber knob, which is the moiety within the Ad capsid responsible for high-affinity attachment of virus to cellular receptors. We used recombinant fiber knob domains from members of group C and B Ads to purify virus interacting proteins from cell membrane lysates and from human and mouse plasma. Using tandem mass spectrometry, we identified a number of candidate Ad-interacting proteins, including functional cellular receptors and previously unknown interacting partners such as complement component C4-binding protein and other blood proteins that presumably are involved in $\mathrm{Ad}$ infection after intravenous virus application. The ability of these proteins to bind to Ad was further confirmed using in vitro protein binding assays as well as infection competition assays. The approach of using a structural protein can be universally applied for a variety of viral and nonviral pathogens and can reveal host cell factors critical in viral infection, immune evasion, and tissue specificity. This information is also a prerequisite to assess in vivo safety and efficacy of Ad-based gene transfer vectors.
\end{abstract}

Key Words: Serotype 5; serotype 35; fiber; tandem mass spectrometry; C4BP; Coxsackie and adenovirus receptor; CD46.

\section{Introduction}

Pathogens, viral or otherwise, remain a major public health concern, accounting for high levels of morbidity and mortality throughout the world (1). Despite knowing the modes of transmission, clinical manifestations, and, in some cases, the entire genome of many of these pathogens, we still struggle to understand structures and mechanisms involved in pathogen-host interaction. For many emerging pathogens, such as the SARS virus, an important first goal

From: Methods in Molecular Medicine, Vol. 131:

Adenovirus Methods and Protocols, Second Edition, vol. 2:

Ad Proteins, RNA, Lifecycle, Host Interactions, and Phylogenetics

Edited by: W. S. M. Wold and A. E. Tollefson (c) Humana Press Inc., Totowa, NJ 
is to identify how the virus chooses which cells to infect and what molecules facilitate this recognition (2-4). This information can provide insight into how the virus affects the host (through defined cellular signaling, for example) and can aid in the development of novel therapeutics against the virus.

The binding of a pathogen to its cellular receptor, however, is only one aspect of how a pathogen interacts with a host. For example, many pathogens travel via the bloodstream to their target tissues and while in transit can complex to one of many molecules in the blood that can serve to deliver the pathogen to a host tissue or even protect the pathogen from immune surveillance and subsequent destruction $(5,6)$. Elucidating these pathways of infection is crucial for understanding the tropism of pathogens and developing therapies for infectious diseases.

Adenovirus (Ad) is a double-stranded DNA virus that is known to cause a variety of benign infections in immunocompetent individuals and more severe diseases in the immunocompromised $(7,8)$. Ad has also recently been used extensively as a gene-delivery vector in part because of its ability to transduce a wide range of target cells. There are 51 known serotypes of human Ad, and these are grouped into groups A to F (9). Viruses from different groups have different cell tropism, in part because of the usage of different attachment receptors. For many Ads, including serotypes from all groups except B, the Coxsackie and adenovirus receptor (CAR) can serve as a primary cellular attachment protein (10-12). Group B Ads, however, do not use CAR, and until recently their cellular receptor remained unknown (13-15).

It is becoming increasingly clear that knowledge of cellular receptors for $\mathrm{Ad}$ does not fully explain their tropism when applied systemically into hosts $(16,17)$. After intravenous injection, CAR-interacting Ads can accumulate in liver macrophages despite the lack of functional receptors on these cells. Recent studies show that this process of liver infection is mediated by blood factors, and the identification of these proteins will be important in predicting and controlling Ad infection in vivo (18).

While it is clear that these host-pathogen interactions are important, there has not yet been a systematic, high-throughput way of identifying these interactions. Until now, investigators have relied on methods such as the yeast-two hybrid screening to identify interacting proteins. Although this method is powerful and can give insight into protein-protein interactions, it has limitations stemming from the expression of mammalian proteins in a yeast system. For many proteins, mammalian-specific modifications are central to their biological function. Further, proteins often function in complexes with other proteins or in multimers, and this type of analysis is difficult in twohybrid systems. Other researchers have relied on scientific intuition, painstak- 
ing biochemical analysis of a variety of proteins, or fortuitous discovery to identify candidate proteins $(3,4,14)$.

Here we employed tandem mass spectrometry (MS/MS) to help facilitate identification of possible interactions of host proteins with Ad. We used Ad from serogroup C (type 5) and serogroup B (type 35) to identify interacting proteins. We first produced recombinant protein of the viral polypeptide of these Ads known to be important for host interactions. We then conjugated these proteins to agarose beads and used this complex to purify proteins from cellular membrane proteins or freshly isolated mouse plasma. The purified proteins were then analyzed using MS/MS to identify candidate proteins. Once these proteins were identified, additional assays were used to verify that proteins identified can truly interact with the viral polypeptide. We describe here techniques used to study the interaction between Ad serotype 5 or 35 fiber knobs and cell or plasma proteins. Similar studies can be performed with other serotypes and with other capsid proteins.

\section{Materials}

1. pQE30 bacterial expression system (Qiagen).

2. Ad fiber knob cDNA (see Note 1).

3. Escherichia coli strain M15pREP4 (Qiagen).

4. Oligonucleotide DNA primers.

5. Restriction enzymes, T4 DNA ligase.

6. Agarose and DNA electrophoresis apparatus.

7. LB medium.

8. Ampicillin and Kanamycin.

9. Isopropyl- $\beta$-D-thio-galactopyranoside.

10. $\mathrm{Ni}^{2+}$-NTA agarose beads (Qiagen).

11. Dulbecco's phosphate-buffered saline (PBS).

12. Dialysis bags, molecular-weight cutoff $=14,000$ (Spectrum Labs).

13. Streptavidin-agarose.

14. Phenylmethylsulfonyl fluoride (PMSF).

15. BiotinTag Biotinylation Kit (Sigma).

16. Sephadex-G15 columns.

17. Resuspension solution: $250 \mathrm{~m} M$ sucrose, $0.1 \%$ Triton X-100.

18. Dounce homogenizer.

19. Protease inhibitor cocktail (Sigma).

20. Membrane protein buffer: $1 \mathrm{~m} M$ Tris- $\mathrm{HCl}, \mathrm{pH} 7.5,+2 \%$ protease inhibitor cocktail.

21. RIPA buffer: $150 \mathrm{mM} \mathrm{NaCl}, 1 \% \mathrm{NP}-40,0.5 \%$ sodium deoxycholate, $50 \mathrm{~m} M$ Tris- $\mathrm{HCl}, \mathrm{pH} 8.0,1 \mathrm{~m} M$ ethylene diamine tetraacetic acid (EDTA), $\mathrm{pH} \mathrm{8.0,}$ $1 \mathrm{~m} M$ PMSF.

22. Avertin (2-2-2 tribromoethanol) (Sigma). 
23. Saline.

24. Tween-20.

25. Imidazole.

26. 2X Laemmli buffer.

27. Sodium dodecyl sulfate-polyacrylamide gel electrophoresis (SDS-PAGE) apparatus.

28. Extravidin, horseradish peroxidase-conjugated avidin (Sigma).

29. ECL Western blotting detection kit (Amersham).

30. BCA protein concentration assay kit (Pierce).

31. Microcon filters, YM-10 (Millipore).

32. Ammonium bicarbonate.

33. Ultrapure acetonitrile.

34. Destaining solution: $15 \mathrm{~m} M \mathrm{~K}_{3} \mathrm{Fe}(\mathrm{CN})_{6}$ and $50 \mathrm{~m} M \mathrm{Na}_{2} \mathrm{~S}_{2} \mathrm{O}_{3}$.

35. Trypsin.

36. Cover solution: $50 \mathrm{mM} \mathrm{NH} \mathrm{HCO}_{3}, 5 \mathrm{mM} \mathrm{CaCl}$.

37. $50 \%$ Acetonitrile.

38. $1 \%$ Tetrafluoroacetic acid.

39. Zip-Tip reverse-phase $\mathrm{C} 18$ columns (Millipore).

40. Sequencing grade-modified porcine trypsin (Promega).

41. Glacial acetic acid.

42. Finnigan LCQ liquid chromatography/MS (Finnigan).

43. MS/MS data analysis program (Sequest, distributed by Thermo Finnigan, and Mascot, distributed by Matrix Science).

44. PBS-T: PBS containing $0.1 \%$ Tween- 20.

45. PBS-T plus $5 \%$ milk.

\section{Methods}

For the successful identification of proteins that interact with a known viral ligand, the following methods can be used to:

1. Produce recombinant virus bait protein.

2. Conjugate bait to appropriate agarose beads.

3. Use bait-bead complexes to precipitate proteins from cell lysates or plasma/serum.

4. Identify interacting proteins with mass spectrometry.

5. Verify interactions by viral competition experiments (Fig. 1).

\subsection{Expression of Recombinant Viral Proteins}

The methods used to produce recombinant viral proteins thought to be important for protein interactions is described elsewhere (19). We describe here the production of recombinant fiber knob. Briefly, the following steps are for producing adenoviral fiber knob domains with a 6-histidine tag at the $\mathrm{N}$-terminus of the protein.

1. Use PCR primers directed to the fiber knob domain of the Ad fiber, including the last repeat of the shaft (see Note 1), to amplify the region and then digest using 


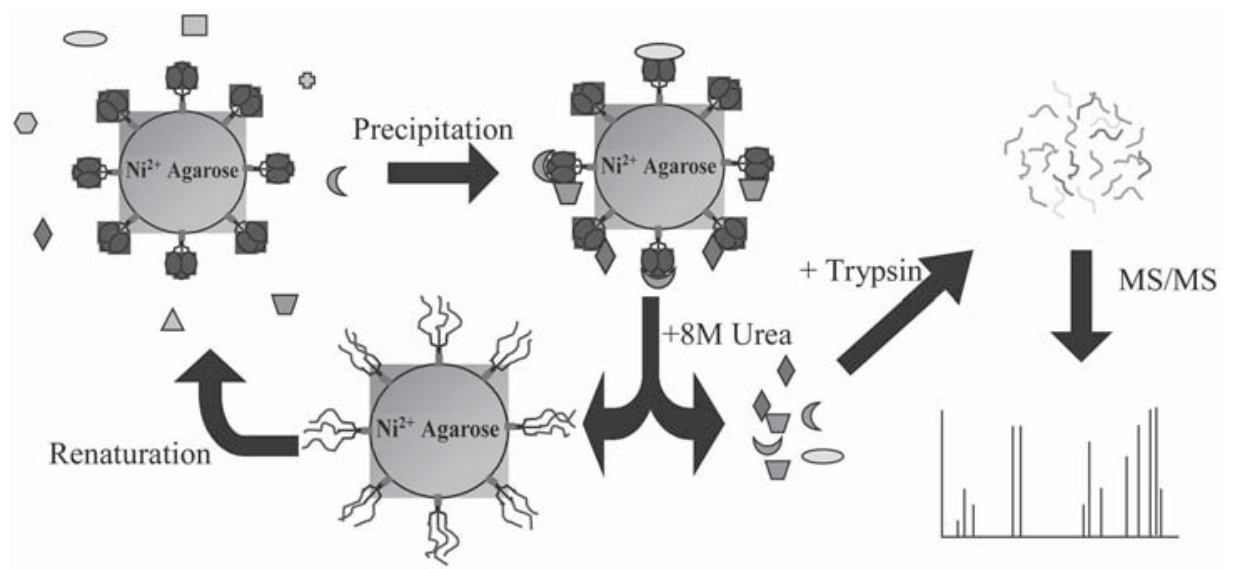

Fig. 1. Schematic showing conjugation of viral fiber knobs via six-His tag to $\mathrm{Ni}^{2+}$ agarose beads, binding of specific proteins and not unrelated proteins and subsequent elution of bound proteins with $8 M$ urea followed by trypsin digestion and tandem mass spectrometry analysis.

appropriate restriction enzymes (in this case, HindIII and BamHI) to facilitate in-frame-cloning into $\mathrm{pQE30}$, which will place a 6-histidine tag at the N-terminus. (Primers to amplify Ad5 fiber knob were 5'-TTT AAG GAT CCG GTG CCA TTA CAG TAG GAA-3' and 5'-TAT ATA AGC TTA TTC TTG GGC AAT GTA TGA-3' and those for Ad35 were 5'-TTT AAG GAT CCG GTG ACA TTT GTA TAA AGG ATA G-3' and 5'-TAT ATA AGC TTA GTT GTC GTC TTC TGT AAT-3') $(\mathbf{1 9 , 2 0 )}$.

2. After cloning and verification by sequencing, transfect the resulting plasmid into M15(pRep4) bacteria.

3. After $1 \mathrm{~h}$ of growth at $37^{\circ} \mathrm{C}$, induce protein expression by adding $1 \mathrm{~m} M$ isopropyl- $\beta$-D-thio-galactopyranoside and incubating for an additional $4-5 \mathrm{~h}$.

4. After lysing bacteria and separating cellular debris, use $\mathrm{Ni}^{2+}{ }_{-} \mathrm{NTA}$ agarose beads to purify expressed proteins under nondenaturating conditions as described by the manufacturer.

5. Dialyze the resulting proteins overnight in PBS $+17 \%$ glycerol and store at $-20^{\circ} \mathrm{C}$.

\subsection{Conjugation of Viral Protein to Agarose}

Because there are several ways to conjugate the viral protein to agarose, we describe here two methods, each with advantages and disadvantages. One strategy involves the addition of a biotin tag onto the recombinant protein, and the other takes advantage of the 6-histidine tag present at the N-terminus of the molecule. Relative advantages and disadvantages of each method are discussed in Note 1. 


\subsubsection{Conjugation of Biotinylated Viral Protein to Streptavidin-Agarose}

1. Mix $100 \mu \mathrm{L}$ of dialyzed fiber knob domain in a 1.5-mL Eppendorf tube with $10 \mu \mathrm{L}$ of biotinylation reagent (BiotinTag, prepared according to manufacturer's protocols) for $30 \mathrm{~min}$ at room temperature on a shaker.

2. Stop the reaction with the addition of $10 \mu \mathrm{L}$ of $1 M$ Tris buffer, $\mathrm{pH} 7.4$, and purify the tagged protein using Sephadex-G15 columns to remove excess biotinylation reagent.

3. Measure the protein concentration of the biotinylated fiber knob domain using the BCA protein concentration assay reagent.

4. Place 5-10 $\mu \mathrm{g}$ of the biotinylated Ad fiber knob domain in $200 \mu \mathrm{L}$ of ice-cold PBS and mix with $20 \mu \mathrm{L}$ streptavidin agarose beads in a shaker for $1-2 \mathrm{~h}$ at $4{ }^{\circ} \mathrm{C}$.

5. Pellet the mixture at $150 \mathrm{~g}$ in a microcentrifuge and wash with $1 \mathrm{~mL}$ ice-cold PBS twice to remove unbound fiber knob protein. Store the resultant pellet at $4^{\circ} \mathrm{C}$.

\subsubsection{Conjugation of His-Tagged Viral Protein to $\mathrm{Ni}^{2+}-\mathrm{NTA}$ Agarose Beads}

1. Mix 10-20 $\mu \mathrm{g}$ dialyzed fiber knob domain with $50 \mu \mathrm{L}$ of $\mathrm{Ni}^{2+}$-NTA agarose beads slurry in $500 \mu \mathrm{L}$ total volume, made up with ice-cold PBS, for $2 \mathrm{~h}$ at $4^{\circ} \mathrm{C}$ on a shaker.

2. Pellet the mixture at $150 \mathrm{~g}$ in a microcentrifuge and wash with $1 \mathrm{~mL}$ ice-cold PBS twice to remove unbound fiber knob protein.

\subsection{Isolation of Cellular Membrane Proteins}

In order to identify membrane proteins capable of binding to a viral polypeptide, cell membrane proteins were prepared according to established protocols (21). Briefly, the methods used were as follows:

1. Grow cells known to be susceptible to virus infection (e.g., HeLa cells, a cervical carcinoma-derived cell line) to confluence in standard $150-\mathrm{mm}$ tissue culture dishes (see Note 2).

2. Scrape cells from each dish into $5 \mathrm{~mL}$ of ice-cold PBS $+1 \mathrm{mM}$ PMSF. Repeat for at least six dishes and keep the cell suspension on ice.

3. Combine cell suspensions and pellet cells in a centrifuge at $300 g$ to remove excess supernatant and resuspend the resultant pellet in $5 \mathrm{~mL}$ of ice-cold resuspension solution.

4. Lyse cells with 30 strokes of a Dounce homogenizer on ice, and pellet at $400 \mathrm{~g}$ for 15 min to remove cellular debris.

5. Collect the supernatant and centrifuge at $100,000 \mathrm{~g}$ for $1 \mathrm{~h}$ in Beckman ultraclear centrifuge tubes with total volume of $13.2 \mathrm{~mL}$ made up with ice-cold PBS.

6. Resuspend the pellet (containing membrane proteins) in $100 \mu \mathrm{L}$ per $150-\mathrm{mm}$ dish of membrane protein buffer. 


\subsection{Isolation of Serum Proteins}

In order to identify proteins within mouse plasma that are capable of interacting with the Ad fiber knob domain, we isolated fresh mouse plasma according to the following protocol.

1. Anesthetize C57 BL/6 mice with intraperitoneal Avertin injections.

2. Collect $800 \mu \mathrm{L}$ of blood from cardiac puncture from each mouse into a $1-\mathrm{mL}$ syringe containing $200 \mu \mathrm{L}$ of saline $+20 \mathrm{~m} M$ EDTA.

3. Immediately centrifuge the sample for $5 \mathrm{~min}$ at $2000 \mathrm{~g}$.

4. Transfer the supernatant (plasma) to a new tube and add Tween-20 and imidazole to final concentrations of $0.1 \%(\mathrm{v} / \mathrm{v})$ and $5 \mathrm{~m} M$, respectively.

\subsection{Precipitation of Interacting Proteins to a Viral Polypeptide}

Once the viral protein has been conjugated to the agarose beads (see Subheading 3.3.), precipitation of proteins is done.

1. Preclear freshly isolated plasma proteins or cell membrane proteins by incubating with either $100 \mu \mathrm{L}$ of unconjugated $\mathrm{Ni}^{2+}$-NTA agarose beads or $50 \mu \mathrm{L}$ of unconjugated strepavidin-agarose beads (depending on labeling technique of the viral polypeptide) in a total volume of $1 \mathrm{~mL}$ made up with ice-cold $\mathrm{PBS}$ at $4{ }^{\circ} \mathrm{C}$ for $2 \mathrm{~h}$ ( see Note 3 ).

2. Centrifuge the sample at $150 \mathrm{~g}$ for $5 \mathrm{~min}$. Add the supernatant, containing precleared proteins, to bead-conjugated fiber knob domains (see Subheading 3.2.) and place on a shaker at $4^{\circ} \mathrm{C}$ for $2 \mathrm{~h}$.

3. Pellet agarose beads at $300 g$ and wash with ice-cold PBS (see Note 4) at least four times to reduce contamination with unbound proteins (see Note 5).

\subsection{Isolation of Proteins From Complexes}

Proteins bound to the Ad fiber knob domain are eluted from the complexes by one of two different techniques. For precipitations using the biotinylated fiber knob, protein complexes are disrupted by boiling. For those complexes formed using a 6-histidine tag, elution was done in the presence of $8 M$ urea to disrupt protein-protein interactions. Each application is suited for specific situations (as discussed in Note 1).

\subsubsection{Isolation of Precipitated Proteins From Biotin-Streptavidin Complexes}

1. Following the last wash step from Subheading 3.5., step 3, boil the complexes with $20 \mu \mathrm{L} 2 \mathrm{X}$ Laemmli Buffer for 5 min.

2. Load the entire sample for separation using electrophoresis in $7 \%$ polyacrylamide SDS-PAGE.

3. Silver stain the protein gel according to established protocols (see Note 6) (22). 
4. Cut bands corresponding to proteins of interest from the gel, and destain with $400 \mu \mathrm{L}$ of destaining solution for 8 min with vigorous shaking.

5. After four 8-min washes with ultrapure water, use pure acetonitrile to dry gel pieces with a Speed-vac for $30 \mathrm{~min}$.

6. Add $0.5-1.0 \mu \mathrm{g}$ of trypsin at $100 \mathrm{ng} / \mu \mathrm{L}$ in $1 \mathrm{mM} \mathrm{HCl}$ and add cover solution as needed to keep gel bits moist on ice for $1 \mathrm{~h}$.

7. Discard excess solution and add $30 \mu \mathrm{L}$ of cover solution and incubate for $12-15 \mathrm{~h}$ at $37^{\circ} \mathrm{C}$.

8. After incubation, collect the supernatant and sonicate sample with $30 \mu \mathrm{L}$ of $20 \mathrm{mM}$ $\mathrm{NH}_{4} \mathrm{HCO}_{3}$ for $15 \mathrm{~min}$ and collect supernatant.

9. Extract residual peptides with three successive sonications in the presence of $30 \mu \mathrm{L}$ of $50 \%$ acetonitrile $+1 \%$ tetrafluoroacetic acid, collecting the supernatant after each sonication.

10. Dry the samples in a Speed-vac to about $5 \mu \mathrm{L}$ and use exchange chromatography resins (Zip-Tip) to purify peptides from salts that can interfere with subsequent analysis.

11. Analyze peptides using high-performance liquid chromatography separation followed by MS/MS analysis.

\subsubsection{Isolation of Precipitated Proteins From 6-His-Ni ${ }^{2+}-\mathrm{NTA}$ Agarose Complexes}

1. Following the last wash step (Subheading 3.5., step 3), incubate complexes with $200 \mu \mathrm{L}$ of $8 M$ urea, which disrupts protein-protein interactions but leaves 6 -His$\mathrm{Ni}^{2+}$-NTA interactions intact.

2. In order to allow for optimal trypsin activity, urea is removed by increasing the volume to $500 \mu \mathrm{L}$ using PBS and concentrating the solution using Microcon filters with a molecular weight cutoff of 3000 Daltons (see Note 7).

3. Digest concentrated protein samples in solution overnight using $0.5-1.0 \mu \mathrm{g}$ trypsin in a total volume of $50 \mu \mathrm{L}$ with final concentrations of $100 \mathrm{~m} M \mathrm{NH}_{4} \mathrm{HCO}_{3}$ and urea concentration less than $2 M$ in an incubator.

4. Quench the reaction after $12-14 \mathrm{~h}$ with the addition of $2 \mu \mathrm{L}$ glacial acetic acid and store frozen until ready for analysis.

5. Recover peptides by using exchange chromatography resins (Zip-Tip) to purify peptides from salts that can interfere with subsequent analysis.

6. Analyze peptides using high-performance liquid chromatography separation followed by MS/MS analysis.

Figure 2 shows a silver-stained SDS-PAGE separation of proteins from Subheading 3.6.2., step 1, along with identified proteins from MS/MS analysis.

\subsection{Verification of Interactions}

To further determine if proteins found through the above process can in fact interact with the Ad fiber knob, several addition verification experiments were done. Using cell membrane proteins, CD46 was determined to be a candidate 


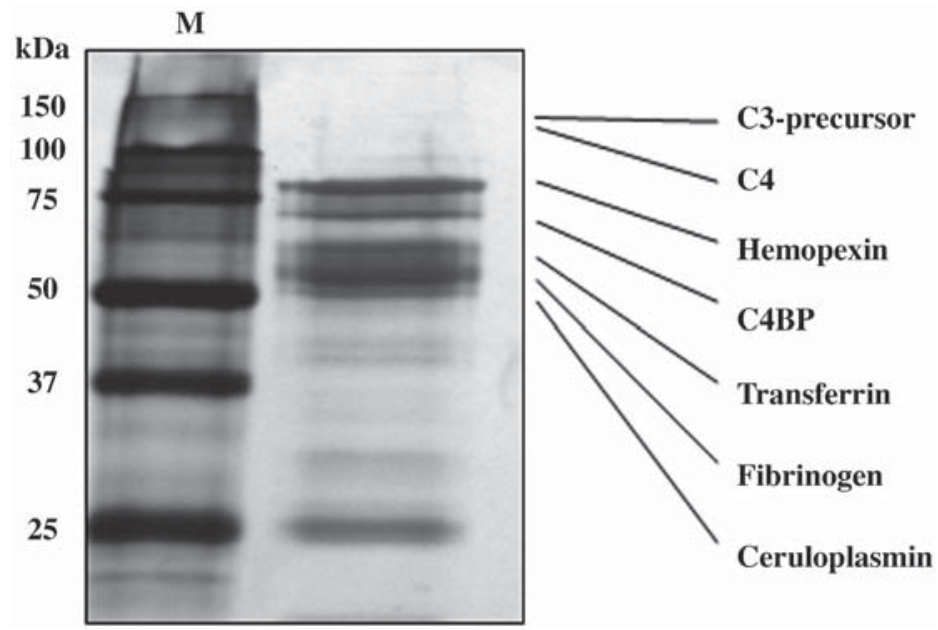

Fig. 2. Silver-stained gel showing molecular-weight markers (M) and proteins isolated from viral knob precipitations along with protein identity revealed by tandem mass spectrometry.

cellular receptor for group B Ads. Detailed experiments, including infection competition studies with soluble CD46 or reduction of infection with siRNA knockdown of receptor expression, verifying this finding can be found elsewhere (15). Further verification of interacting proteins from mouse serum was performed (18). In the first experiment, we used virus overlay protein blot assays to assess binding of purified proteins to Ad fiber knob domains. We then used one of the identified proteins, C4-binding protein (C4BP), in further analyses of binding to determine if it could compete for virus infection in vitro.

\subsubsection{Verifying Protein-Protein Binding Using Virus Overlay Protein Blot Assays}

1. Immobilize $5-10 \mu \mathrm{g}$ of recombinant proteins identified by MS/MS analysis on nitrocellulose membrane.

2. Incubate membrane overnight with $5 \%$ milk in PBS $+0.1 \%$ Tween (PBS-T) at $4^{\circ} \mathrm{C}$.

3. Wash membrane once with PBS-T.

4. Dilute biotinylated fiber knob domain (Subheading 3.2.1., step 3) in PBS-T + $0.5 \%$ milk to final concentration of $1-2 \mu \mathrm{g} / \mathrm{mL}$ and add to washed membrane for $1 \mathrm{~h}$ with gentle shaking at room temperature

5. After washing several times with PBS-T, add avidin diluted 1:1000 in PBS-T + $0.5 \%$ milk and incubate for $30 \mathrm{~min}$ at room temperature.

6. Wash several times with PBS-T and develop using ECL reagent (as per manufacturer's directions). 


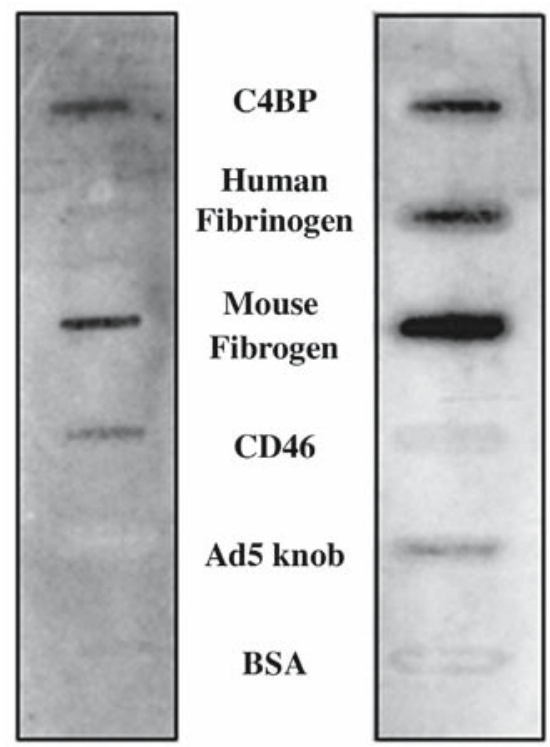

Fig. 3. Slot blot assay showing a panel of proteins probed with adenovirus (Ad)35 (left panel) or Ad5 knobs (right panel) to assess binding. BSA, bovine serum albumin.

Results in Fig. 3 represent analysis using the Ad5 or Ad35 fiber knobs as probes.

\subsubsection{Infection Competition Experiments With C4BP and Ad5/35}

Chinese hamster ovary (CHO) cells are refractory to Ad infection; however, when stably transfected to express Ad attachment receptors, they become permissive for infection with the virus. While infection of CHO-CAR with Ad5 in the presence of physiological concentrations of C4BP and other plasma proteins did not demonstrate change in virus infectivity (data not shown), C4BP could efficiently compete infection of $\mathrm{CHO}-\mathrm{C} 2$ cells ( $\mathrm{CHO}$ cells expressing the $\mathrm{C} 2$ isoform of CD46) with an Ad35 fiber-containing vector (Ad5/35) (Fig. 4A) (23).

1. Plate $2 \times 10^{5} \mathrm{CHO}-\mathrm{C} 2$ cells in 12 -well plates and allow them to grow overnight.

2. Use purified Ad5/35 expressing green fluorescence protein (GFP) under the control of the cytomegalovirus promoter at a multiplicity of infection of $10 \mathrm{PFU} /$ cell and add to cells in the presence of increasing amounts of C4BP in a total volume of $500 \mu \mathrm{L}$ growth medium and incubate at $37^{\circ} \mathrm{C}$ for $3 \mathrm{~h}$ (see Note 9) (24).

3. Wash cells several times with PBS and incubate in growth medium overnight.

4. Assess GFP fluorescence of cells using fluorescence microscope and/or flow cytometry analysis. 

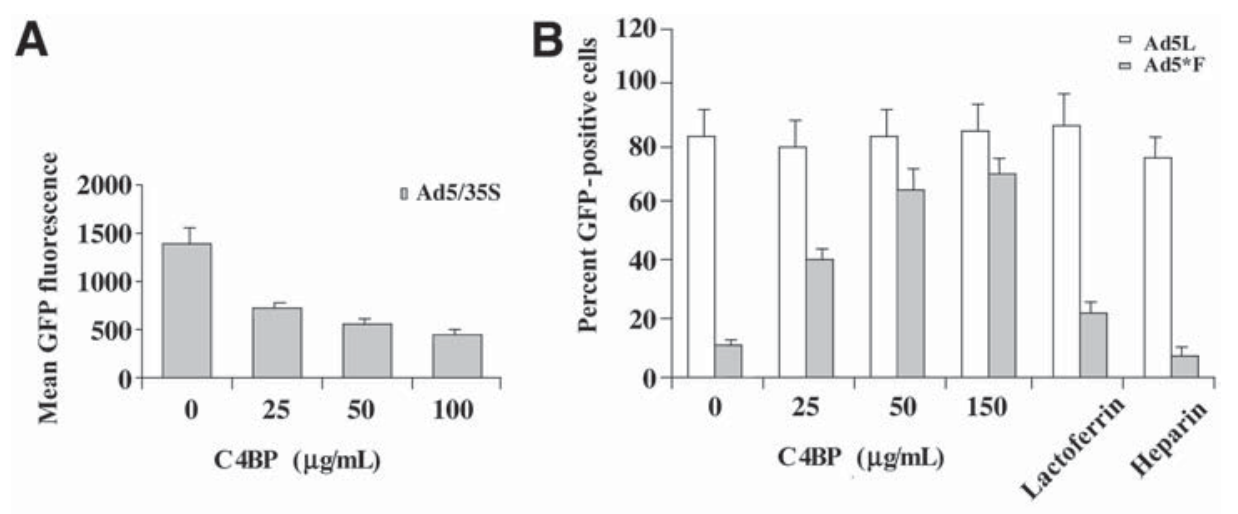

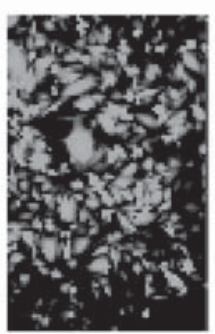

Control

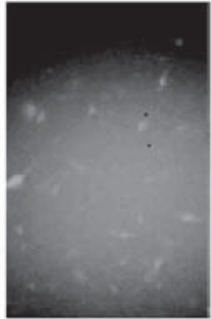

$+\mathrm{C} 4 \mathrm{BP}$

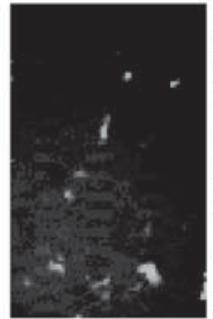

Control

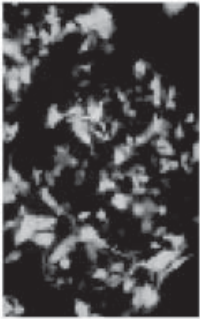

$+\mathrm{C} 4 \mathrm{BP}$

Fig. 4. (A) Infection competition of Chinese hamster ovary (CHO)-C2 cells in the presence of $\mathrm{C} 4$ binding protein (C4BP). Quantification of $\mathrm{CHO}-\mathrm{C} 2$ cell infection by Ad5/35 by fluorescence-activated cell sorting in the presence of various concentrations of C4BP is shown in the upper panel. Representative cells infected with Ad5/35 with or without $100 \mu \mathrm{g} / \mathrm{mL}$ of C4BP are shown in the lower panel. (B) Infection enhancement of HepG2 cells in the presence of C4BP. Quantification of HepG2 infection by $\mathrm{Ad} 5 * \mathrm{~F}$ by FACS at various concentrations of $\mathrm{C} 4 \mathrm{BP}$ and at highest $\mathrm{C} 4 \mathrm{BP}$ levels in the presence of lactoferrin or heparin (upper panel) with representative cells infected with Ad5*F with or without $100 \mu \mathrm{g} / \mathrm{mL}$ of C4BP (lower panel).

\subsubsection{Infection Competition Experiments With C4BP and $A d 5^{*} F$}

To analyze whether the infectivity of Ad can be modulated by interactions with plasma proteins identified through our approach, we infected human hepatocarcinoma cells, HepG2 (see Note 10), with an Ad5-based vector, Ad5 ${ }^{*} \mathrm{~F}$ (possessing a single point mutation abolishing its binding to its cellular receptor CAR $[16,25]$ ), in the presence of purified plasma proteins. This analysis revealed that when cells were infected with $\mathrm{Ad} 5 * \mathrm{~F}$, few cells expressed the virus-encoded transgene GFP (Fig. 4B, $0 \mu \mathrm{g} / \mathrm{mL}$ C4BP). However, when $\mathrm{Ad} 5 * \mathrm{~F}$ infection was conducted in the presence of $\mathrm{C} 4 \mathrm{BP}$, a marked increase in vector infectivity toward these cells was observed (Fig. 4B, C4BP). 
1. Plate $2 \times 10^{5} \mathrm{HepG} 2$ cells in 12-well plates and allow to grow overnight.

2. Use purified $\mathrm{Ad} 5^{*} \mathrm{~F}$ at a multiplicity of infection of $50 \mathrm{PFU} / \mathrm{cell}$ and add to cells in the presence of increasing amounts of C4BP (up to $250 \mu \mathrm{g} / \mathrm{mL}$, which is the physiological level in human plasma) in a total volume of $300 \mu \mathrm{L}$ growth medium and incubate at $37^{\circ} \mathrm{C}$ for $3 \mathrm{~h}$.

3. Wash cells several times with PBS and incubate in growth medium overnight.

4. Assess GFP fluorescence of cells using fluorescence microscope or flow cytometry analysis.

Here we demonstrate that using a straightforward high-throughput approach, novel functional interactions of a virus with host factors can be identified. Using Ad receptor-interacting fiber knob domain as bait, we recovered and identified a protein, $\mathrm{C} 4 \mathrm{BP}$, from whole mouse plasma that modulates virus infectivity toward both susceptible (CHO-C2 for Ad5/35) and resistant (HepG2 for $\mathrm{Ad} 5 * \mathrm{~F}$ ) cell types. It should be noted that the other proteins identified through MS/MS analysis were confirmed to bind to Ad fiber knob domain in slot-blot assays, and future studies will determine the functional role of these interactions. Despite the complexity of mouse plasma protein composition, we were able to rapidly identify new Ad-interacting partners, which will have implications for Ad vector development. The approach of using a structural protein to identify host factors critical in viral infection, immune evasion, and tissue specificity can be universally applied for a variety of viral and nonviral pathogens and can reveal new targets for prospective therapies.

\section{Notes}

1. Ad DNA for amplification of the fiber knob domain was extracted using standard DNA extraction techniques from purified viral particles of wild-type Ad of various serotypes. Fiber knob domains were amplified using primers encompassing the last repeat of the shaft domain and the entire fiber knob domain. The last repeat of the shaft is necessary because it is required for proper trimerization of the recombinant protein.

2. Biotinylation of proteins using the described methods adds a biotin molecule to the lysine residues throughout the peptide. This can theoretically aid in recovery because a single protein can have multiple biotinylation sites that can be used for precipitation, allowing for increased yield. Disadvantages of this technique include an added manipulation of the purified protein. Specifically, biotinylation of lysine residues that are important in protein-protein interactions might affect the outcome of this method. Testing if the biotinylated protein can still bind to a protein of interest (by either competitive experiments or virus overlay protein blot assays) can help to confirm if a protein retains functionality after biotinylation. The use of the 6-histidine tag also has advantages and disadvantages. The advantages include less manipulation of the protein because it has an incorporated tag as well as the fact that it is likely not involved in interactions because it is (in this example) far from putative interaction sites. Another advan- 
tage is that elution of precipitated proteins can be done without contamination with bait proteins (see Fig. 1). The disadvantages include a potentially weak signal, with only one bait protein per polypeptide, that may not be readily accessible in nondenatured conditions. Further, the $\mathrm{Ni}^{2+}$-agarose beads are not compatible with certain conditions that may be required for protein purification (such as increased EDTA solutions).

3. Using epithelial cell lines such as HeLa cells can often produce large amounts of keratins that tend to contaminate MS/MS samples. The choice of cell type can be determined by identifying those cells likely to produce abundant receptor molecules (e.g., by infectivity assays).

4. Depending on the type of beads used, a second preclearing round can be done, especially if the beads appear to bind to proteins abundant in plasma.

5. To reduce nonspecific binding to $\mathrm{Ni}^{2+}$-NTA beads, add $10 \mathrm{mM}$ imidazole to the wash solution. Also, if nonspecific background binding is high, consider washing samples with PBS in the presence of a nonionic detergent, such as $0.1 \%$ NP-40.

6. It is especially important to wash many times when using serum proteins because the abundant proteins like albumin can often contaminate samples even after four washes if less abundant proteins are being analyzed.

7. For better likelihood of successful identification by MS/MS analysis, do not fix the gel with formaldehyde during silver staining.

8. Urea can disrupt trypsin activity and, if this contaminant is too high, will result in suboptimal peptide recovery. A second concentration step can be performed in the same microcon container by again increasing the volume to $500 \mu \mathrm{L}$ using PBS and concentrating to $50 \mu \mathrm{L}$. Also, the molecular-weight cutoff of the filter can be adjusted to enrich in particular weights of target proteins.

9. These experiments utilized the convenience of pseudotyped vectors with an easily assayable transgene. These experiments can also be performed with wild-type Ad using cytopathic effect as a primary outcome instead of GFP transgene expression.

10. The choice of HepG2 as a cell line was made because of previous observations that liver infection in vivo by Ad5-based vectors is not CAR dependent and likely is mediated by other serum factors. Using a vector abolished for CAR-binding, we are better able to assay the contribution of our newly discovered blood factors to infection of these human liver-derived cells in the absence of CAR binding.

\section{References}

1. World Health Organization. (2003) World Health Report, Geneva, Switzerland.

2. Li, W., Moore, M. J., Vasilieva, N. et al. (2003) Angiotensin-converting enzyme 2 is a functional receptor for the SARS coronavirus. Nature 426, 450-454.

3. Tatsuo, H., Ono, N., Tanaka, K., and Yanagi, Y. (2000) SLAM (CDw150) is a cellular receptor for measles virus. Nature 406, 893-897.

4. Wang, X., Huong, S. M., Chiu, M. L., Raab-Traub, N., and Huang, E. S. (2003) Epidermal growth factor receptor is a cellular receptor for human cytomegalovirus. Nature 424, 456-461. 
5. Agnello, V., Abel, G., Elfahal, M., Knight, G. B., and Zhang, Q. X. (1999) Hepatitis $C$ virus and other flaviviridae viruses enter cells via low density lipoprotein receptor. Proc. Natl. Acad. Sci. USA 96, 12,766-12,771.

6. Hilgard, P. and Stockert, R. (2000) Heparan sulfate proteoglycans initiate dengue virus infection of hepatocytes. Hepatology 32, 1069-1077.

7. Ruuskanen, O., Meurman, O., and Akusjarvi, G. (2002) Adenoviruses, in Clinical Virology (Hayden, F. G., ed.), ASM Press, Washington, DC, pp. 515-535.

8. Hierholzer, J. C. (1992) Adenoviruses in the immunocompromised host. Clin. Microbiol. Rev. 5, 262-274.

9. Shenk, T. (2001) Adenoviridae, in Fields Virology, 4th ed. (Knipe, D. M. and Howley, P.M., eds.), Vol. 2, Lippincott Williams and Wilkins, Philadelphia, PA, pp. 2265-2301.

10. Bergelson, J. M., Cunningham, J. A., Droguett, G., et al. (1997) Isolation of a common receptor for Coxsackie B viruses and adenoviruses 2 and 5. Science 275, 1320-1323.

11. Roelvink, P. W., Lizonova, A., Lee, J. G., et al. (1998) The coxsackievirus-adenovirus receptor protein can function as a cellular attachment protein for adenovirus serotypes from subgroups A, C, D, E, and F. J. Virol. 72, 7909-7915.

12. Tomko, R. P., Xu, R., and Philipson, L. (1997) HCAR and MCAR: the human and mouse cellular receptors for subgroup $\mathrm{C}$ adenoviruses and group B coxsackieviruses. Proc. Natl. Acad. Sci. USA 94, 3352-3356.

13. Sirena, D., Lilienfeld, B., Eisenhut, M., et al. (2004) The human membrane cofactor CD46 is a receptor for species B adenovirus serotype 3. J. Virol. 78, 4454-4462.

14. Segerman, A., Atkinson, J. P., Marttila, M., Dennerquist, V., Wadell, G., and Arnberg, N. (2003) Adenovirus type 11 uses CD46 as a cellular receptor. J. Virol. 77, 9183-9191.

15. Gaggar, A., Shayakhmetov, D. M., and Lieber, A. (2003) CD46 is a cellular receptor for group B adenoviruses. Nat. Med. 9, 1408-1412.

16. Alemany, R. and Curiel, D. T. (2001) CAR-binding ablation does not change biodistribution and toxicity of adenoviral vectors. Gene Ther. 8, 1347-1353.

17. Martin, K., Brie, A., Saulnier, P., Perricaudet, M., Yeh, P., and Vigne, E. (2003) Simultaneous CAR- and alpha V integrin-binding ablation fails to reduce Ad5 liver tropism. Mol. Ther. 8, 485-494.

18. Shayakhmetov, D. M., Gaggar, A., Ni, S., Li, Z. Y., and Lieber, A. (2005) Adenovirus binding to blood factors results in liver cell infection and hepatoxicity. J. Virol. 79, 7478-7491.

19. Zinn, K. R., Douglas, J. T., Smyth, C. A., et al.. (1998) Imaging and tissue biodistribution of $99 \mathrm{mTc}$-labeled adenovirus knob (serotype 5). Gene Ther. 5, 798-808.

20. Shayakhmetov, D. M., Li, Z. Y., Ternovoi, V., Gaggar, A., Gharwan, H., and Lieber, A. (2003) The interaction between the fiber knob domain and the cellular attachment receptor determines the intracellular trafficking route of adenoviruses. J. Virol. 77, 3712-3723. 
21. Wu, E., Fernandez, J., Fleck, S. K., Von Seggern, D. J., Huang, S., and Nemerow, G. R. (2001) A 50-kDa membrane protein mediates sialic acid-independent binding and infection of conjunctival cells by adenovirus type 37. Virology 279, 78-89.

22. Gharahdaghi, F., Weinberg, C. R., Meagher, D. A., Imai, B. S., and Mische, S. M. (1999) Mass spectrometric identification of proteins from silver-stained polyacrylamide gel: a method for the removal of silver ions to enhance sensitivity. Electrophoresis 20, 601-605.

23. Oglesby, T. J., White, D., Tedja, I., et al. (1991) Protection of mammalian cells from complement-mediated lysis by transfection of human membrane cofactor protein and decay-accelerating factor. Trans. Assoc. Am. Physicians 104, $164-172$.

24. Shayakhmetov, D. M., Papayannopoulou, T., Stamatoyannopoulos, G., and Lieber, A. (2000) Efficient gene transfer into human CD34(+) cells by a retargeted adenovirus vector. J. Virol. 74, 2567-2583.

25. Roelvink, P. W., Mi Lee, G., Einfeld, D. A., Kovesdi, I., and Wickham, T. J. (1999) Identification of a conserved receptor-binding site on the fiber proteins of CAR-recognizing adenoviridae. Science 286, 1568-1571. 